\title{
O estimulo à prática da interdisciplinaridade e do multiprofissionalismo: a Extensão Universitária como uma estratégia para a educação interprofissional
}

Andréa Catelan Cardoso*; Daniela Jorge Corralo**; Mônica Krahl***; Leonardo Porto Alves****

\author{
Acadêmica de Odontologia da Universidade de Passo \\ Fundo, extensionista, bolsista PAIDex. \\ ** Professora do curso de Odontologia da Universidade de \\ Passo Fundo, coordenadora do projeto de extensão \\ "Atenção às famílias de Proprietários de Cavalos de \\ Carroça". \\ *** Professora do curso de Enfermagem da Universidade de \\ Passo Fundo, extensionista. \\ **** Professor do curso de Medicina Veterinária da \\ Universidade de Passo Fundo, extensionista.
}

\section{RESUMO}

A educação interprofissional (EIP) tem se apresentado como uma estratégia para formar profissionais com perfil para o trabalho em equipe, essencial para a integralidade do cuidado em saúde. Este estudo descreve a prática da EIP nas atividades desenvolvidas no projeto de extensão "Atenção às famílias dos proprietários de cavalos de carroça do município de Passo Fundo-RS", o qual tem como objetivos promover saúde e geração de renda para as famílias de catadores de lixo deste município, assim como estimular a consolidação da reorientação da formação profissional nos cursos da área da saúde da Universidade de Passo Fundo. O projeto é desenvolvido nas comunidades dos bairros Bom Jesus e Valinhos desde 2011. O trabalho em equipe multiprofissional com abordagens interdisciplinares permite aos acadêmicos experienciar competências e habilidades esperadas durante a formação acadêmica, como liderança, tomada de decisões, comunicação e atenção à saúde, dentro dos
\end{abstract}

princípios da ética/bioética, buscando a resolução dos problemas de saúde em nível individual e coletivo. A ampliação do conhecimento e experiência, a experimentação do trabalho interdisciplinar e humanizado em imersão na comunidade, o estreitamento de laços entre a universidade e a comunidade, assim como formação técnico-científica humanizada foram citadas pelos extensionistas como contribuições à formação profissional. As atividades desenvolvidas pelo projeto de extensão mostraram ser um método oportuno de estimulo à interdisciplinaridade e ao multiprofissionalismo, proporcionando atendimento social e de saúde às famílias envolvidas e contemplando a formação de um profissional ético, humanista, crítico e consciente do seu papel como cidadão.

Descritores: Relações ComunidadeInstituição. Educação em Saúde. 


\section{INTRODUÇÃO}

A Extensão Universitária, numa perspectiva pedagógica, objetiva estimular a visão multidimensional, em que as esferas político-social-humana estejam presentes na formação acadêmica do aluno extensionista, promovendo o estímulo da consciência crítica, definida sob a perspectiva de Freire $(2009)^{1}$ como a capacidade de correlacionar coisas e fatos sobre as situações casuais e circunstanciais. $O$ artigo 43 da lei $n^{\circ} 9.394^{2}$ define que a educação superior tem a finalidade de estimular o espírito científico e o pensamento reflexivo do universitário por meio do ensino, da pesquisa e da extensão, segundo os princípios da indissociabilidade onde estão inseridas a justiça social, a solidariedade e a cidadania $^{3-5}$.

Silva e Vasconcelos $(2006)^{5}$ consideram que a educação superior no Brasil prioriza o ensino e a pesquisa sem considerar as atividades de extensão como indispensáveis para a formação profissional. Bartnik e Silva (2009) ${ }^{3}$ afirmam que a relação universidadesociedade é construída a partir da preocupação mais sistematizada com o meio social em que está inserida, não apenas pelo ensino e pela pesquisa, mas principalmente pela extensão. Sendo a universidade a base do desenvolvimento cientifico e tecnológico, serve de pilar para o dinamismo cientifico nas sociedades atuais.

Este conhecimento, quando associado a uma contextualização da realidade, estimula o olhar comparativo e critico acerca das diferenças entre as mesmas, contemplando as peculiaridades culturais de cada grupo, pressupondo que, se a compreensão da realidade for crítica, a ação também o será1.

De acordo com Morais (1989) ${ }^{6}$ " os contextos culturais dos povos dão formas muito peculiares a seus problemas concretos". Esta ideia culmina na problematização que é permitida nas vivências proporcionadas pela extensão, pelo contato com diferentes comunidades dentro da singularidade das mesmas. Já o conhecimento científico se coloca como um grande desafio no século XXI, sustentado pela ordem, a regularidade, a constância e o determinismo absoluto. A união destes alicerces impulsiona a compreensão dos fenômenos humanos, na perspectiva sociocultural e em sua relação com o meio ambiente ${ }^{7}$.

O contato com um meio distinto ao que o acadêmico está inserido enaltece a formação multifocal contemplando a capacidade de aprender a ensinar enquanto ensina ${ }^{8}$, de forma a disseminar o aprendido no meio cientifico às comunidades que não possuem acesso a este, de forma condizente com suas realidades, exercendo a postura de guia e não de detentor do conhecimento $^{1,5}$.

Cortella $(2003)^{9}$ contempla este pensamento, ressaltando o arsenal de conhecimento de propriedade destas pessoas que se fazem suficientes para a sobrevivência diária, onde um impacto na mudança de suas ações coletivas poderia fragilizá-los. Freire $(2011)^{10}$ refere a "impossibilidade de dicotomizar o homem do mundo, pois não existe um sem o outro", ao fato de que a extensão deve ser um ato de transferência e não de imposição. Esta simbiose permite considerar Extensão Universitária como uma via de mão dupla de forma a contextualizar a realidade por meio do impacto cultural, que contribui para a formação de profissionais proativos, 
tolerantes, com capacidade de negociação e senso de relevância.

Lobato et al. $(2012)^{11}$ consideram pesquisa, extensão e interdisciplinaridade elementos de grande importância para o progresso do conhecimento científico e para a formação de profissionais altruístas, éticos, tecnicamente capacitados e munidos de uma curiosidade criativa, indagadora e sempre insatisfeita de um sujeito ativo, capaz de reconhecer a realidade inconstante, livre de preconceitos. Isto requer a transição da consciência ingênua, que considera a realidade estática, tem posições tendenciosas e é impermeável à investigação, para a consciência crítica ${ }^{12-14}$.

Outros autores também apontam a consciência coletiva como a consciência do próprio tempo, que estimula os indivíduos a refletir acerca de suas representações sociais, permitindo a universalização da forma de ver e pensar sobre seu mundo ${ }^{5,15}$.

A prática extensionista não se resume à ampliação do quadro de referências culturais, mas a uma integração de conhecimentos que estimula o sentido do respeito ao outro, o sentido da tolerância e faz com que os acadêmicos participem plenamente da prática constante de aprender, integrando os conhecimentos científicos adquiridos na universidade às peculiaridades das famílias e suas comunidades, considerando seus hábitos e costumes culturais. Os processos de ensino-aprendizagem não se resumem a operações individualizadas numa mecânica intelectual, mas faz convergirem emoções, afetos mútuos, ou seja, pressupõe vários atores que tecem agenciamentos entre o já estabelecido e as novidades científicas e informacionais ${ }^{16}$.

Morin $(2005)^{7}$ considera que cultura não é saber tudo sobre um pequeno ponto, e tampouco é saber pequenos pontos sobre tudo, mas sim, é o que justifica e integra conhecimentos. Classes mais desfavorecidas possuem riqueza do conhecimento cultural, mas precariedade em conhecimentos mais elaborados ${ }^{9}$. Este nicho de informações pode ser um campo para a prática da educação interprofissional (EIP), estimulando o trabalho em equipe e a integralidade do cuidado em saúde.

A implantação das Diretrizes Curriculares Nacionais ${ }^{17}$ ainda é um desafio aos currículos dos cursos superiores em saúde. Mecanismos efetivos de integração curricular ainda estão em desenvolvimento e a prática da EIP tem se apresentado como uma estratégia para formar profissionais com perfil para o trabalho em equipe, prática essencial para a integralidade do cuidado em saúde ${ }^{18}$.

Este estudo propõe-se a descrever a prática da EIP nas atividades desenvolvidas no projeto de extensão “Atenção as famílias dos proprietários de cavalos de carroça do município de Passo Fundo-RS", o qual tem como objetivo promover saúde e geração de renda por meio da inserção universitária multiprofissional na realidade das famílias de catadores de lixo deste município.

\section{RELATO DE EXPERIÊNCIA}

O projeto de extensão "Atenção às famílias de proprietários de cavalos de carroça do município de Passo Fundo-RS" iniciou suas atividades em março de 2011, a partir de uma demanda verificada pelos professores e acadêmicos do curso de Medicina Veterinária, integrantes do projeto "SOS Cavalos de Carroça". Ao assistir aos cavalos dos carroceiros, se 
percebeu que as famílias estavam desassistidas de cuidados básicos de saúde e de assistência social. A proposta para atender a estas demandas foi feita ao Centro Universitário de Saúde Coletiva (CEUSC) da Universidade de Passo Fundo (UPF), em setembro de 2010.

O projeto proposto pelo CEUSC, construído pelos docentes das áreas da saúde e serviço social, com o apoio do PróSaúde II, foi encaminhado à Divisão de Extensão da UPF, sendo aprovado (Ata 257/ $1^{\circ}$ dezembro 2010) e iniciando as atividades no ano de 2011. A equipe do projeto é formada por professores e acadêmicos dos cursos Enfermagem, Psicologia, Medicina Veterinária, Nutrição, Fisioterapia e Odontologia. As atividades são realizadas nas comunidades de catadores de lixo dos bairros Bom Jesus e Valinhos.

As ações propostas pelo projeto de extensão visam possibilitar às famílias usuárias do projeto o acesso às políticas sociais públicas, tais como assistência social, saúde, previdência social, habitação e educação, contribuindo com o desenvolvimento integral das famílias e o fortalecimento de seus vínculos. O projeto objetiva, ainda, o fortalecimento da consolidação da reorientação da formação profissional nos cursos da área da saúde da UPF ampliando a integração ensinoserviço, a busca pela integralidade e qualidade da atenção à saúde e o trabalho em equipe multiprofissional com abordagens interdisciplinares.

A equipe multiprofissional participa das atividades nas comunidades realizando o reconhecimento das famílias (comunidade assistida pelo projeto de extensão do curso de Medicina Veterinária) e o levantamento das necessidades sociais e de saúde a partir de questionários aplicados sob a forma de entrevistas. Estas informações permitem à equipe fazer uma leitura da realidade destas comunidades. A partir da demanda percebida, são construídas propostas de ações específicas para cada comunidade pela equipe do projeto, estimulando aos acadêmicos o exercício da profissão articulado ao contexto social destas famílias.

Desde o ano de 2011, a atuação de acadêmicos e professores dos cursos da área da saúde envolvidos no projeto de extensão tem propiciado o exercício de diferentes competências e habilidades pela equipe. No campo de trabalho (na realidade vivenciada) os acadêmicos podem experienciar a liderança, a tomada de decisões, a comunicação e a atenção à saúde, dentro dos princípios da ética /bioética, buscando a resolução dos problemas de saúde em nível individual e coletivo.

De acordo com as avaliações dos acadêmicos, foram citadas como contribuições à formação profissional a ampliação do conhecimento e experiência; a experimentação do trabalho interdisciplinar e humanizado em imersão na comunidade; o estreitamento de laços entre a universidade e a comunidade; assim como formação técnico-científica humanizada.

Algumas aprendizagens durante a permanência no projeto, conforme afirmado pela equipe, foram a interdisciplinaridade; a melhora no comportamento interprofissional; a interação com outras áreas de conhecimento; a educação popular; e, acima de tudo, a experiência que só pode ser percebida pelo contato com as famílias, proporcionado pela extensão. 
De acordo com a experiência acadêmica, o aprendizado decorrente das relações entre as diferentes áreas é extremamente essencial para a formação profissional de cada voluntário envolvido no projeto. $\mathrm{O}$ conhecimento obtido contribui para uma formação técnica, mas também para a formação de um cidadão perante toda a sociedade, pois o conhecimento de diferentes áreas é algo relevante para exercer de maneira mais segura, ética e crítica a profissão na área da saúde.

\section{CONSIDERAÇÕES FINAIS}

A desigualdade na distribuição da renda se reflete no acesso da população ao espaço urbano: a população com maior renda possui o privilégio de escolher os melhores locais para instalar-se, enquanto que a população com renda inferior não possui esta prerrogativa ${ }^{19}$. Fatos que corroboram com a segregação sócioespacial caracterizam a divisão do espaço urbano das cidades, de forma a concentrar as diferentes classes sociais em determinadas regiões: de um lado, pessoas com alto poder aquisitivo e de mobilidade, formando a "cidade legal" dotada de infraestrutura; do outro, a classe formada por um contingente populacional em situação de vulnerabilidade, formando as "cidades ilegais" desprovidas de equipamentos, serviços e de infraestrutura; constituindo em um espaço isolado dentro do contexto da cidade ${ }^{20}$, cuja inexistência de uma política de desenvolvimento integrado ocasiona desequilíbrios, que acentuam as diferenças. Diferenças, aliás, que também são visíveis na contraposição de recursos pedagógicos restritos às relações acadêmicas de caráter tecnicista, segmentada, acrítica e com pouca reflexão
- o que ainda se constata em cursos de Odontologia - e interfaces pautadas pela complexidade do múltiplo, que constitui os diversos contextos sociais, irredutíveis aos moldes acadêmicos ${ }^{21,22}$. Não obstante, projetos de extensão inserem o acadêmico nesta realidade, muitas vezes diferente da qual se encontra implantado, o que the permite amplitude de visão do mundo, conferindo ao extensionista o papel de um ser disseminador, que entende e respeita as diferenças.

As atividades realizadas durante a prática da extensão promovem a integração entre as múltiplas profissões na busca por um aprendizado não fragmentado e o estreitamento da relação universidadecomunidade de forma multiprofissional e interdisciplinar, que possibilita ao acadêmico uma visão que abrange o ser humano como um todo e não de forma reducionista e fragmentada, indo além da obtenção de conhecimentos técnicocientíficos, tendo em vista que esses se tornam superficiais quando não associados à realidade ${ }^{5}$.

A extensão permite que os acadêmicos aprimorem as habilidades técnicas adquiridas academicamente, consubstanciando a prática interporfissional e permitindo que os extensionistas experimentem o trabalho contíguo na busca pela melhoria da qualidade de vida dessas famílias dentro do contexto sócio-histórico-cultural das mesmas. Segundo Monteiro e Vieira $(2010)^{23}$ a reflexão dada pela vivência com as situações de submissão e acomodação diante da realidade e da passividade acerca do quadro de exclusão em que as famílias da comunidade estão expostas, possibilita ao acadêmico descortinar as limitações e dificuldades pessoais identificadas, 
instigando, assim, a adoção do senso de "consciência coletiva" dos acadêmicos extensionistas.

Essa compreensão estabelece a troca mutua de conhecimento entre extensionistas e comunidade, obtendo respostas positivas da mesma, "superando a pratica tendenciosa do estudo ocioso tão presente no meio universitário, da cultura alienada, enfim, da pesquisa fortuita e sem objetividade"13. A complexidade do viver em sociedade, relacionada a processos cognitivos de âmbito mais subjetivo, contribui para processos educacionais envolvendo sujeitos militantes, conscientes de seu papel pela cidadania ${ }^{24}$. Quando o acadêmico adota a postura de um cidadão preocupado com a realidade social de diferentes contextos da sociedade, torna-se um profissional humanista, crítico e reflexivo.

As atividades extensionistas estimulam a atuação multiprofissional, interdisciplinar e transdisciplinar, promovendo saúde com embasamento cientifico, culminando com aspectos de cidadania e ética, pois reforça a premissa de que todo o profissional da saúde deve exercer sua profissão de forma articulada ao contexto social contribuindo para a transformação da realidade em benefício da sociedade ${ }^{17}$. Isto impacta positivamente os serviços de saúde que, hoje reféns de certo engessamento laboral - muito pela fragmentação dos conhecimentos, ou seja, por conta de uma cultura corporativista -, são carentes de subjetividades ativas na transformação da sociedade ${ }^{24}$.

De acordo com as avaliações dos acadêmicos, a experimentação do trabalho interdisciplinar e humanizado em imersão na comunidade é uma das contribuições da extensão à formação profissional e representa uma experiência única. Neste aspecto, o acadêmico pode reconhecer a riqueza do conhecimento cultural de cada comunidade e complementar os conhecimentos específicos a partir da educação em múltiplos enfoques, como saúde, assistência social, educação, dentre outros.

Esta experiência mostrou ser a extensão um campo favorável para a prática da EIP, essencial para construir a relação universidade-sociedade ${ }^{3}$. A indissociabilidade do ensino, pesquisa e extensão devem ser estimuladas durante a educação superior, pois este tripé reforça a formação integral e adequada do estudante, congregando distintas competências e habilidades necessárias aos profissionais da saúde, mantendo reconhecido padrão de ética e conduta em todos os aspectos da vida profissional ${ }^{3-5,17}$.

Ademais, a educação em saúde é permanente, o que torna crucial o desassossego de padrões de pensamento estabelecidos, nem sempre imbricados no dia-a-dia das coletividades: eis o ensejo para a anulação das fronteiras entre educação e saúde, o que se promove nas interfaces entre educação e cidadania ${ }^{16,22}$. A prática da EIP nas atividades desenvolvidas no projeto de extensão "Atenção às famílias dos proprietários de cavalos de carroça do município de Passo Fundo-RS" mostrou ser um método oportuno de estimulo à prática da interdisciplinaridade e do multiprofissionalismo, proporcionando atendimento social e de saúde às famílias envolvidas e contemplando a formação de um profissional ético, humanista, crítico e consciente do seu papel como cidadão. 


\section{REFERÊNCIAS}

1. Freire P. Educação como prática da liberdade. Rio de Janeiro: Paz e Terra, 2009.

2. Brasil. Lei n. 9394 de 20 de dezembro de 1996. Estabelece as diretrizes e bases da educação nacional. Senado Federal, Brasília, 1996.

3. Bartnik FMP, Silva IM. Avaliação da ação extensionista em universidades católicas e comunitárias. Avaliação (Campinas; Sorocaba). 2009;14(2) :453-6 9.

4. Hennington EA. Acolhimento como prática interdisciplinar num programa de extensão universitária. Cad Saúde Pública. 2005; 21(1):256-65.

5. Silva MS, Vasconcelos SD. Extensão Universitária e formação profissional: avaliação da experiência das Ciências Biológicas na Universidade Federal de Pernambuco. Est Aval Educ. 2006;17(33):119-36.

6. Morais R. Cultura brasileira e educação. Campinas: Ed Papirus, 1989.

7. Morin E. Educação e complexidade: os sete saberes e outros ensaios. 3ed. São Paulo: Editora Cortez, 2005.

8. Freire P. Pedagogia da autonomia saberes necessários à prática docente. 19ed. São Paulo: Paz e Terra, 1996.

9. Cortella MS. A escola e o conhecimento: fundamentos epistemológicos e políticos. 7ed. Editora Cortez. São Paulo, 2003.

10. Freire P. Extensão ou comunicação? 15ed. Rio de Janeiro: Paz e Terra, 2011.

11. Lobato PLM, Abranches M, Rodrigues TVA. Indissociabilidade ensino, pesquisa e extensão no projeto Rondon ${ }^{\circledR}$ Minas Resíduos Sólidos.
VII Seminário de Extensão Universitária - PUC Minas, 2012 [acessado em 28 abr. 2013]. Disponível em: http://www1.puc minas. br/documentos/forext_02.pdf.

12. Freire P. Educação e mudança. 6ed. Rio de Janeiro: Paz e Terra, 1983.

13. Melo Neto JF. Extensão universitária e produção do conhecimento. Conceitos. 2003; 5(8):13-9.

14. Mitre SM, Batista RS, Mendonça JMG, Pinto NMM, Meirelles CAB, Porto CP, et al. Metodologias ativas de ensino-aprendizagem na formação profissional em saúde: debates atuais. Ciênc saúde colet. 2008;13(Supll 2):2133-44.

15. Bazzanella SL, Favéri JE. A consciência ingênua como pressuposto e perfil da educação regional. Luminária (União da Vitória - PR). 2012;13:19-33.

16. Ceccim RB, Ferla, AA. Educação e saúde: ensino e cidadania como travessia de fronteiras. Trab educ saúde, 2009;6(3):443-56.

17. Brasil, Resolução CNE/CES 3 de 19 de fevereiro de 2002. Institui Diretrizes Curriculares Nacionais do Curso de Graduação em Odontologia. Conselho Nacional de Educacão, Câmara de Educação Superior, Brasília, 2002.

18. Batista NA. Educação Interprofissional em Saúde: Concepções e Práticas. Caderno FNEPAS. 2012;2:528.

19. Olimpio CC, Malta FJNC. Desigualdade de renda e segregação socioespacial no município de Pindamonhangaba-SP. XIII Encontro de Iniciação Científica e IX Mostra de Pós-graduação; 2008 out 6-11; 
Pindamonhangaba, SP. [acessado em 28 abr. 2013]. Disponível em: http://site.unitau.br/scripts/prppg/enic 2008/resumos/EPH0606.pdf

20. Pegoretti MS, Sanches SP. A problemática da segregação espacial dos residentes na área rural: uma visão através da dimensão acesso e do sistema de transporte. II Encontro Nacional de Pós-graduação e Pesquisa em Ambiente e Sociedade; 2004, Campinas, SP. [acessado em 28 abr. 2013]. Disponível em: http://www.anppas.org.br/encontro_a nual/encontro2/GT/GT11/michela.pdf

21. Mello ALSF, Andrade SR, Moysés SJ, Erdmann AL. Saúde bucal na rede de atenção e processo de regionalização. Ciênc Saúde Colet. 2014;19(1):20514.

22. Ferla AA, Ceccim RB, Dall'alba R. Informação, educação e trabalho em saúde: para além de evidências, inteligência coletiva. RECIIS. 2012;6(2):620.

23. Monteiro EMLM, Vieira NFC. Educação em saúde a partir de círculos de cultura. Rev Bras Enferm. 2010;63(3):397-403.

24. Franco TB. Produção do cuidado e produção pedagógica: integração de cenários do sistema de saúde no Brasil. Interface (Botucatu). 2007;11(23): 427-438.

\section{ABSTRACT \\ The incentive to practice of inter disciplinarity and multiprofessionalism: the University Extension as a strategy for interprofessional education}

The interprofessional education (IPE) has emerged as a strategy to train professionals with a profile to teamwork, essential for comprehensive health care. This study describes the practice of the EIP activities in the extension project "Attention to the families of wagon horses' owners in the city of Passo Fundo-RS." This project aims to promote health and income generation for the families of garbage collectors, as well as encourage the consolidation of the reorientation of healthcare courses at Passo Fundo University. The project is developed in the communities of Bom Jesus and Valinhos neihborhoods since 2011. Working in multidisciplinary team with inter disciplinary approaches during the academic training allows experiencing academic competencies and skills such as leadership, decision-making, communication and health care, within the principles of ethics/ bioethics, seeking the resolution of health problems at individual and collective level. The knowledge and experience expansion, experimentation of interdisciplinary and humanized work in immersion in the community, closer ties between the university and the community, as well as technical and scientific humanized training were cited by extension as contributions to vocational training. The activities developed by the extension project proved to be an opportune method of stimulating the interdisciplinary and multiprofessionalism, providing social and health care to the families involved and contemplating the formation of ethical, humanist, and critical professionals, aware of their role as citizens.

Descriptors: Community-Institutional Relations. Health Education.

Correspondência para:

Andréa Catelan Cardoso

e-mail: andreaccardoso@bol.com.br

Rua Ramiro Barcelos,487, casa 08

97700-000 - Santiago/RS 